\title{
Auditory primary afferents in the starling: Correlation of function and morphology
}

\author{
O. Gleich \\ Institut für Zoologie der Technischen Universität München, Garching, F.R.G.
}

(Received 20 June 1988; accepted 21 September 1988)

\begin{abstract}
Despite the independent evolution of birds and mammals, a number of structural similarities of their hearing organs have developed in parallel. By tracing the peripheral origin of functionally-characterized primary neurons, the present study demonstrates functional similarities between the respective hair cell populations of the hearing organs of birds and mammals. The space devoted to one octave on the starling's basilar papilla is not constant over the whole length; rather it increases from the apical low- to the basal high-frequency end. The finding that (with the exception of a specialized area near the apical end) only tall hair cells situated on the neural limbus receive active afferent innervation is a functional parallel to the mammalian inner hair cells. The thresholds of afferents increase with distance of the related hair cells from the neural side of the papilla and cover a range of more than $50 \mathrm{~dB}$ within the area of tall hair cells.
\end{abstract}

Starling; Cochlea; Frequency map; Innervation pattern; Hair cell type

\section{Introduction}

A varying degree of differentiation of hair cells over the width of the sensory epithelium within the hearing organ is found in the recent Archosauria (crocodiles and birds) and Mammalia. The organ of Corti in eutherian mammals is, of course, coiled with 1.5 to 4.5 turns; a crosssection generally shows a single row of inner hair cells on the modiolar (inner) side of the epithelium. Three rows of outer hair cells are strictly separated by processes of the inner phalangeal cells from the inner hair cells and lie over the free basilar membrane (Lim, 1986). The organ of Corti in the prototherian mammals (Monotremata) is only slightly curved, with 4 rows of inner hair cells clearly separated by a 'tunnel rod' from 6-9 rows of outer hair cells (Chen and Anderson, 1985). The basilar papilla of birds and crocodiles is also

Correspondence to: O. Gleich, (Present address), Department of Physiology, University of Western Australia, Nedlands 6009, Western Australia, Australia. only slightly curved and the hair cell number increases from the base to the apex. Tall (inner) hair cells are clearly discernible from short (outer) hair cells in the caiman (v. Düring et al., 1974; Leake, 1977). In the birds, however, there is no clear separation between two distinct hair cell populations; tall hair cells on the neural side (corresponding to the inner side) of the epithelium show a gradual transition in morphology to short hair cells on the abneural side (Takasaka and Smith, 1971).

The evolution of the ancestors of both mammalian and archosaurian vertebrate groups started more than 250 million years ago from common reptilian ancestors. The Pelycosauria, ancestors of mammals, were already present in the carboniferous, while the Protorothyridae gave rise to the radiation of the other reptiles (Carrol, 1988). The hearing organs of the stem forms were probably primitive with only one type of hair cell, and may still be represented by the recent Sphenodon and turtles, which can be traced back to the late permian or early triassic times (Miller, 1985); separate hair cell populations are also not found 
across the papilla of lizards and snakes. Thus the differentiation of hair cells over the width of the basilar papilla (Archosauria) and the organ of Corti (Mammalia) is a later phenomenon and probably a result of independent parallel evolution within the vertebrates (Manley et al., 1988a). This has, however, resulted in a number of remarkable structural similarities between the respective hair cell populations. These similarities concern the location of hair cell populations within the papilla, their ontogenetic development, their innervation patterns and their susceptibility to noxious treatment (Manley et al., 1988b). Hair cells on the inner, or neural, side of the epithelium show a predominantly afferent and less prominent efferent innervation, while the opposite is true for outer, or abneural, hair cells. In mammals (only Eutheria are investigated) only $5-10 \%$ of the afferents contact outer hair cells (Spoendlin, 1979). In birds $16-21 \%$ of the afferents are reported to innervate short hair cells (corresponding to outer hair cells; v. Düring et al., 1985), while in the crocodilia $40 \%$ of the afferents supply outer hair cells (Klinke and Pause, 1980).

A number of investigators have tried to correlate functional properties of primary auditory afferents with the anatomical results described above. However, neither in bird (Sachs et al., 1974; Manley et al., 1985) nor in caiman (Klinke and Pause, 1980), where a substantial portion of the afferents supply the different hair cell populations, was it possible to discriminate fibre groups according to their response types which might correspond to different hair cell populations. The failure to find functionally-different afferents was in mammals explained by the finding that active auditory units exclusively innervated inner hair cells (Liberman, 1982b; Robertson, 1984) and some evidence was found that afferents to the outer hair cells do not display any spike activity (Robertson, 1984). In mammals, there is evidence that inner hair cells transfer information via the afferents to the brain while outer hair cells actively modify the input to the inner hair cells through a reverse electromechanical transduction (Mountain, 1986).

In order to investigate the tonotopic organization and the possibility of a functional differentiation of the avian basilar papilla, the synaptic input of functionally-characterized primary auditory afferents was determined in the starling in order to obtain comparative data for birds and to determine whether the structural similarities between the avian and mammalian hair cell populations are reflected in their functional properties.

\section{Methods}

Recordings from cochlear ganglion cells were obtained in wild-caught, anaesthetized starlings (Sturnus vulgaris). Details of the surgical approach to the cochlear ganglion have been described previously (Manley et al., 1985). Upon encountering an auditory unit, the frequencythreshold curve was determined using an automated procedure measuring activity in a matrix of frequency and sound pressure combinations (Gleich and Narins, 1988). The characteristic frequency (the frequency where the lowest sound pressure was required to increase the discharge rate; $\mathrm{CF}$ ), the threshold at $\mathrm{CF}$ and the $Q_{10 \mathrm{~dB}}$-value (CF divided by the bandwidth $10 \mathrm{~dB}$ above threshold at $\mathrm{CF}$ ) were determined from these tuning curves. In addition, an estimate of the spontaneous discharge rate was obtained from the neural activity during $4 \mathrm{~s}$ of tone presentation (40 tone bursts of $100 \mathrm{~ms}$ ) using sound pressure and frequency combinations which lay well outside the response area of the cell, which did not cause an increase of the discharge rate. Thereafter, the cell was labelled with cobalt in order to determine it's synaptic input within the basilar papilla.

Details of the cobalt technique have been described by Köppl and Gleich (1988) and are briefly summarized as follows. Recordings of single-cell activity were obtained using glass micropipettes filled with a $5 \%$ hexamminecobaltic chloride solution and with final resistances between 40 and $100 \mathrm{M} \Omega$. Cobalt ions were iontophoretically applied using positive current pulses (50 ms, $10 \mathrm{~s}^{-1}, 0.5-7 \mathrm{nA}$ ) for 5-30 min. After 1-2.5 h survival time, birds were given an overdose of anaesthetic (Nembutal) and the cobalt was precipitated during a $5 \mathrm{~min}$ transcardial perfusion with a solution containing $1 \%$ ammonium sulfide and $0.9 \% \mathrm{NaCl}$. This was followed by the fixative (4\% formaldehyde in $0.1 \mathrm{M}$ phosphate buffer) for another $15 \mathrm{~min}$. The cochlear duct, including the 
cochlear ganglion and part of the auditory nerve, was then exposed and dissected completely free from the bone, without decalcification. After thoroughly washing out the fixative, an intensification procedure adapted from Bacon and Altman (1977) was performed to make the cobalt-filled profiles visible. After dehydration, the specimens were cleared in methyl-salicylate to allow visualization of the stained fibres.

The whole mounts were analyzed using an inverted microscope (Nikkon Diaphot, $200 \times$ ) with the specimens oriented so that most of the papilla lay within or close to the optical plane. With the optics used, it was possible to recognize the outline of the papilla and focus on hair cells. To measure the length of the papilla, it was divided in 5 or 6 segments and the length of each segment determined by adjusting one end of a calibrated scale within the eye piece to the apical end, the scale running parallel to the neural side of the papilla. By focussing with the calibrated stage of the microscope first on hair cells at one end of the scale and then on those at the other end it was possible to measure the distance between the two optical planes and calculate the true length of the papilla segment between the ends of the scale. The over-all length of the papilla was the sum of the 5-6 segments. This procedure of measurement minimises the errors due to deviations of the papilla from the optical plane and due to the curvature of the epithelium. The distance of labelled terminals from the apical end of the papilla was determined in an analogous way.

After the whole mounts had been completely analyzed, they were transferred to acetone, embedded in Spurr's resin and cut into $15 \mu \mathrm{m}$-thick serial transverse sections. These were mounted on slides and embedded in canada balsam. In these sections, it was possible to determine both the position of the contacted hair cell relative to the neural side of the papilla, and the form of the synaptic ending.

\section{Results}

The cobalt technique was very successful in the starling. From 27 experiments with 36 attempts to label characterized cells, stained cells were found after 34 injections in 25 cochleae. In most experi- ments only one attempt was made to stain a physiologically characterized cell. Two, or in one case three, injections were only performed in experiments when the cells encountered had CFs differing by $1-4$ octaves ( 8 from 25 experiments). The difference in CF and the success in all multiple injections allowed unambiguous assignment of the stained fibres to functional properties recorded before injection.

After 20 injections, only one stained cell was found. 9 of the 14 other injections resulted in 2 stained fibres, and only 5 injections resulted in more than 2 stained fibres within the basilar papilla (Fig. 1a). Almost $90 \%$ of the injections resulted in stained fibres innervating a single hair cell or hair cells separated by less than $3 \%$ of the total papillar length (Fig. 1b). In all cases with more than one stained cell resulting from a single injection, the innervated hair cells were in close proximity on the basilar papilla. In 3 of 9 experiments with attempts to label cells with a $C F \leqslant 0.2 \mathrm{kHz}$, a stained fibre was also encountered running to the macula lagenae.

The length of the basilar papilla in the sample of 25 cochleae as measured in methyl-salicylate was $2.86 \pm 0.11 \mathrm{~mm}$ (range: $2.70-3.18 \mathrm{~mm}$ ). The position of labelled terminals within the papilla was measured as the distance from the apical end and then, for better comparison, normalized to a percentage of the individual papillar length. Repeated measurements revealed a mean error of $3 \%$.

One aim of this study was to investigate the tonotopicity of the starling's basilar papilla. For this purpose, the distance of labelled terminals from the apical end was plotted versus the characteristic frequencies (CF) determined immediately before cobalt injection. The resulting frequency map is shown for the unambiguous single-cell stains in Fig. 2a. Results from cobalt injections with more than one stained cell are shown in Fig. 2b; each stained cell is shown as a cross, cells stained after a single injection are connected. Both plots show a clear tonotopic arrangement, with low frequencies located near the apical end and progressively higher frequencies located more basally. Both data groups were pooled for a regression analysis; in the cases of ambiguous stains, the centre of the stained area was taken for the calculations. The analysis of the 
pooled data $(N=34)$ reveals that they can be well fit by the functions given below; the correlation coefficients are each highly significant $(P<0.001)$, but not statistically different $\left(X^{2}=4.582, \quad p>\right.$ $0.05 ; \mathrm{X}^{2}$-test for comparing correlation coefficients, Zar, 1974).

$d=18.48+(15.66 \times \mathrm{CF})($ linear,$r=0.77)$

$d=40.42+14.34 \times \ln$ CF (logarithmic, $r=0.92)$

$d=41.23 \times \mathrm{CF}^{0.76}$ (power, $r=0.83$ )

$d=$ distance of labelled terminal from the apical end.

These three best-fit functions are shown in Fig. $2 \mathrm{c}$ for comparison. Extrapolation of the functions results of course, in different frequency ranges mapped on the epithelium. The linear function would map frequencies of $0-5.2 \mathrm{kHz}$ on the papilla with $0 \mathrm{~Hz}$ located $18.5 \%$ from the apical end. The logarithmic function covers a frequency range of $0.06-64 \mathrm{kHz}$ with an equal mapping constant of $0.3 \mathrm{~mm}$ per octave over the whole length of the papilla. The power function would map frequencies of $0.3 .2 \mathrm{kHz}$ onto the papilla. Here, as well as for the linear function, the mapping constant changes from $\approx 0.1 \mathrm{~mm}$ per octave near the apical end to $\approx 0.6 \mathrm{~mm}$ per octave near the basal end. The smoothed weighted average (Cleveland, 1979) is shown in Fig. 2d together with the data points used for the calculations. The smoothed average indicates that octaves below $0.5-1 \mathrm{kHz}$ occupy less space on the papilla than higher-frequency octaves, as can be seen by the steeper slope in the low-frequency area as compared to higher frequencies. The single stain at $4.2 \mathrm{kHz}$ is isolated from the other stains and causes the kink in the weighted function at the high frequency end.

The analysis of the whole mounts revealed that almost all labelled fibres running to the basilar papilla $(N=55)$ were unbranched ( 1 exception) and contacted hair cells within the neural third of the epithelium ( 2 exceptions). The branched fibre was one of the two which contacted abneurally-lying hair cells; it innervated about 6 hair cells (Fig. 3). In two additional experiments (which were performed to perfect the cobalt technique) a large cobalt injection was placed in the ganglion using a broken elektrode. All stained
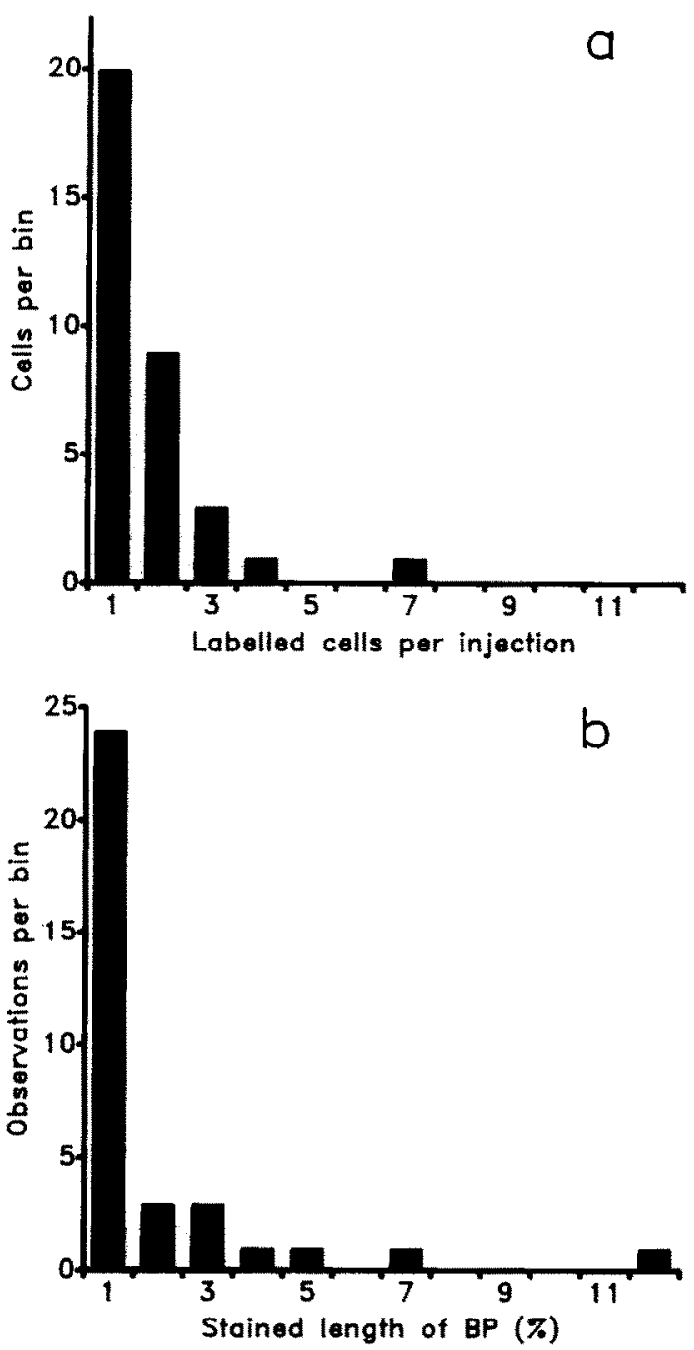

Fig. 1. (a) The number of cells and (b) the percentage of the length of the basilar papilla innervated by the stained cells as the result of single cobalt injections. Almost $90 \%$ of the injections resulted in only 1 or 2 stained fibres which each innervate an area of less than $3 \%$ of the total papillar length.

fibres $(\geqslant 30$ in each case) were unbranched and contacted neurally-lying hair cells.

In order to further quantify this observation, serial sections of the cochleae with labelled fibres were investigated. Some of the specimens were badly damaged during embedding and sectioning, so that from the 34 successful stains only 24 could be analyzed in the cross sections. All stains that had been identified in the whole mounts were also found in the serial sections, with no additional 

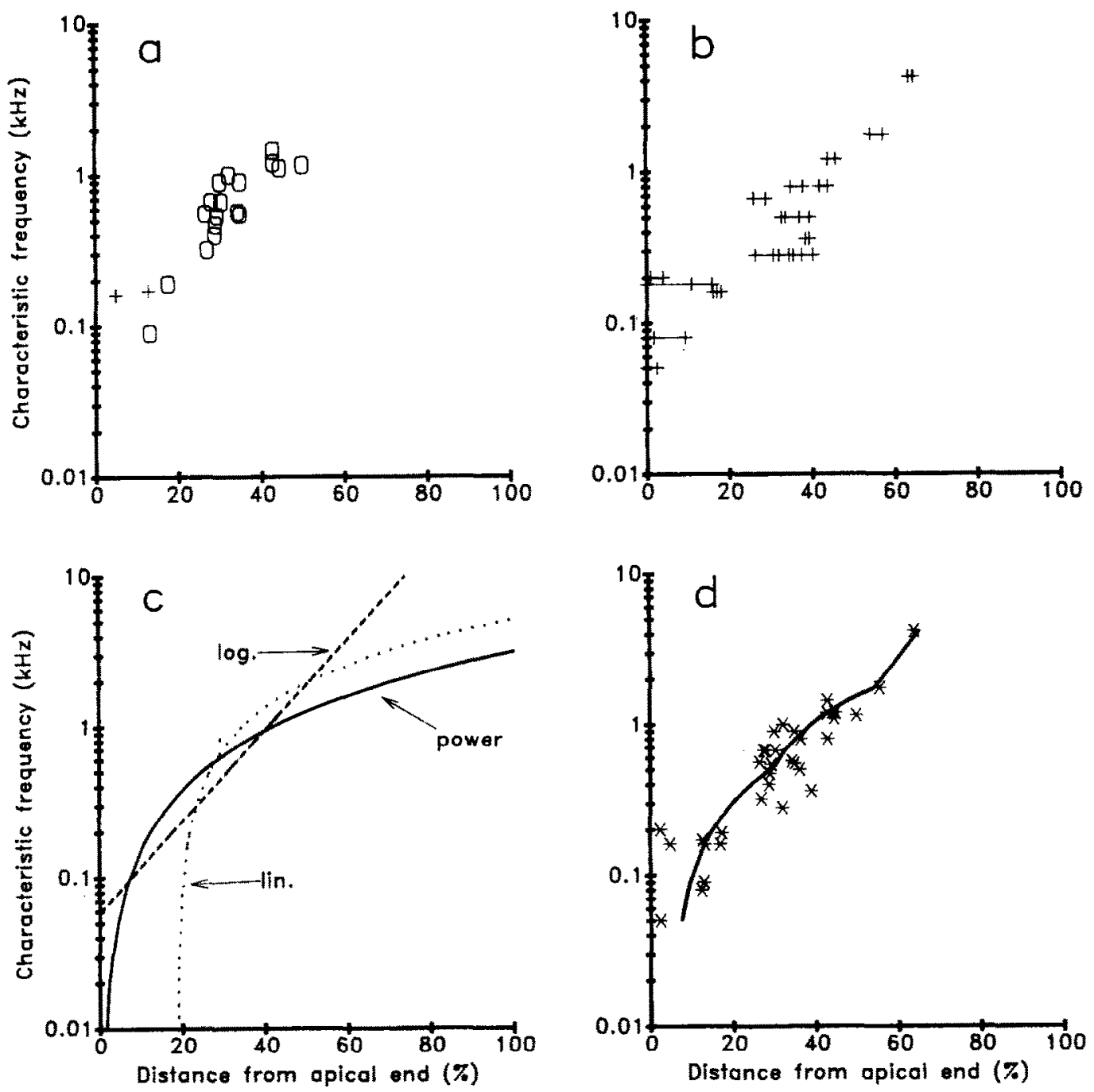

Fig. 2. The distance of labelled terminals from the apical end of the starling papilla as a function of the CF; (a) unambiguous, single-cell stains (crosses indicate the position of the two cells innervating abneurally-lying hair cells, see text) and (b) multiple stains (results of individual injections are connected). (c) Three best-fit functions (linear, logarithmic and power) through the data, with the correlation coefficients each being highly significant $(P<0.001)$, but not statistically different (see text). (d) A smoothed weighted average through the data points used for the calculation (Cleveland, 1979).

stains detectable. Fig. 4a shows a photomicrograph of a stained fibre in a whole mount looking perpendicular to the papilla, and Fig. $4 \mathrm{~b}$ shows the profile of the same fibre in a cross section of the papilla. In cross sections it was possible to identify the hair cell contacted by the stained fibre and to determine the rank of the hair cell relative to the neural side of the papilla by counting hair cells from neural to abneural. Most hair cells innervated by labelled fibres had ranks between 3 and 14; only 2 exceptional cells contacted hair cells with ranks over 20 (abneurally located hair cells; see also Fig. 3). The distribution of hair cell ranks as determined from the cross sections is shown in Fig. 5. The total number of hair cells over the width of the starling papilla varies in the relevant frequency range between roughly 20 and 30 (Gleich and Manley, 1988) and was determined from a serially sectioned reference specimen at a number of distances from the apical end. Fig. 6 

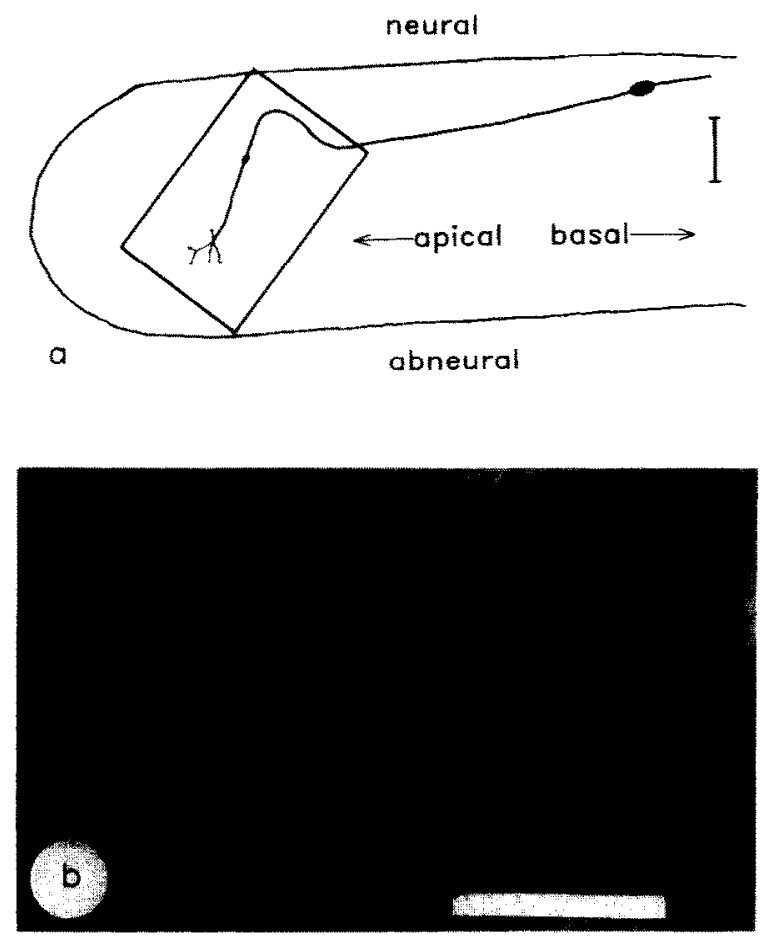

Fig. 3. (a) Schematic outline of the apical end of a papilla showing one of the exceptional fibres which innervated abneurally-lying hair cells (the only fibre which branched). (b) $\mathrm{Mi}$ crophotograph of the detail indicated in the sketch above, showing the terminal area of the fibre. Note (b) is rotated with respect to (a). Calibration bars correspond to $50 \mu \mathrm{m}$.

shows the characteristic frequencies as a function of the hair cell rank. The heavy line shows the position of the edge of the sensory epithelium after converting the distances to best frequencies according to the frequency map described above. The dotted line shows the position where the ratio of hair-cell height and apical hair cell width has the value of 1 ; hair cells to the left of the line are taller (arbitrarily designated as 'tall' hair cells) and those to the right are shorter ('short' hair cells) than a $1: 1$ ratio. With 2 exceptions, all fibres examined innervated tall hair cells. It should be noted that, due to their relatively small surface diameter (Gleich and Manley, 1988), even tall hair cells with a rank of 13 (the highest innervated rank, with the exception of 2 cells) lie within the neural third of the papilla.

The two exceptional cells which innervated abneurally lying hair cells also had unusual re- sponse properties. They were rather insensitive, with thresholds above $70 \mathrm{~dB}$ SPL. In addition, at $20 \mathrm{~dB}$ above their thresholds, they responded over a very wide low-frequency range $(\approx 0.05-1 \mathrm{kHz})$ with a discharge rate increase (Fig. 7). Their tuning curves were extremely flat so that it was hardly possible to determine a CF. Fig. 7 shows the tuning curves of these two cells (dashed and dotted) compared to the tuning curve of a 'normal' cell (continuous line) responding over a similar frequency range but innervating a neurallylying hair cell.

The question arises as to whether the rank of innervated hair cells correlates with any functional
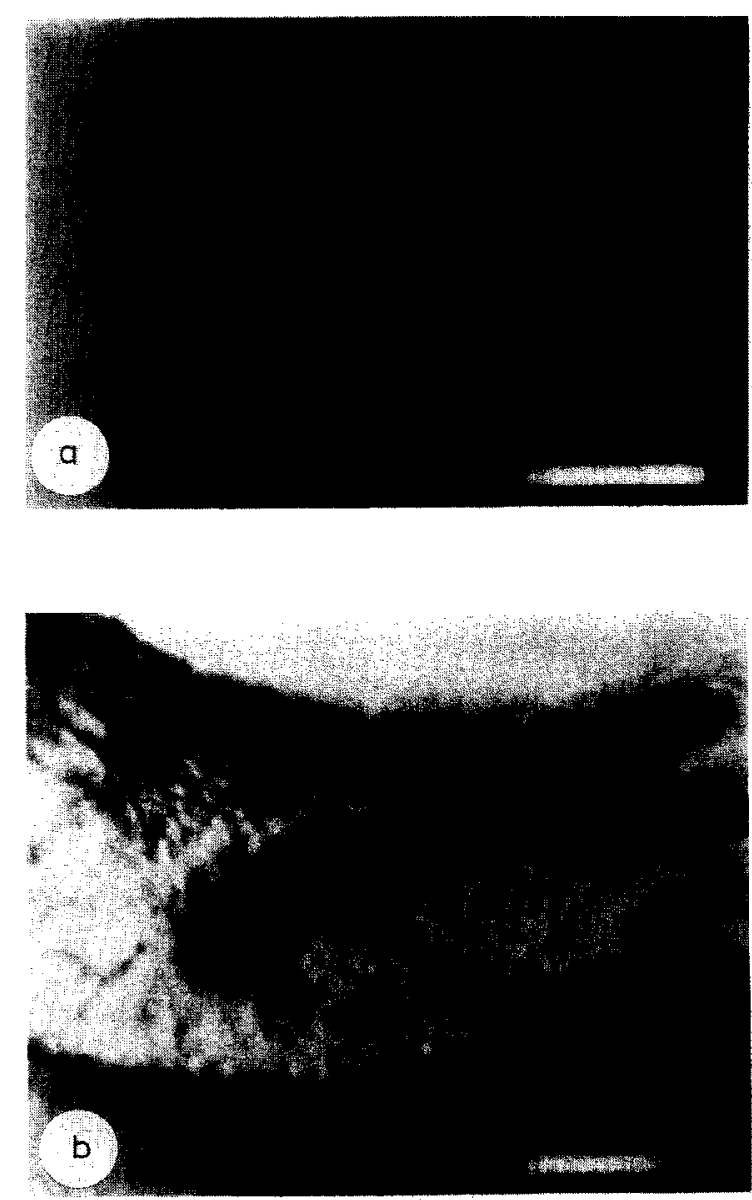

Fig. 4. (a) View from above through a whole mount showing the terminal end of a labelled fibre running from the habenula in a neural direction and innervating a single tall hair cell. (b) The same fibre seen in cross section. Calibration bars correspond to $20 \mu \mathrm{m}$. 


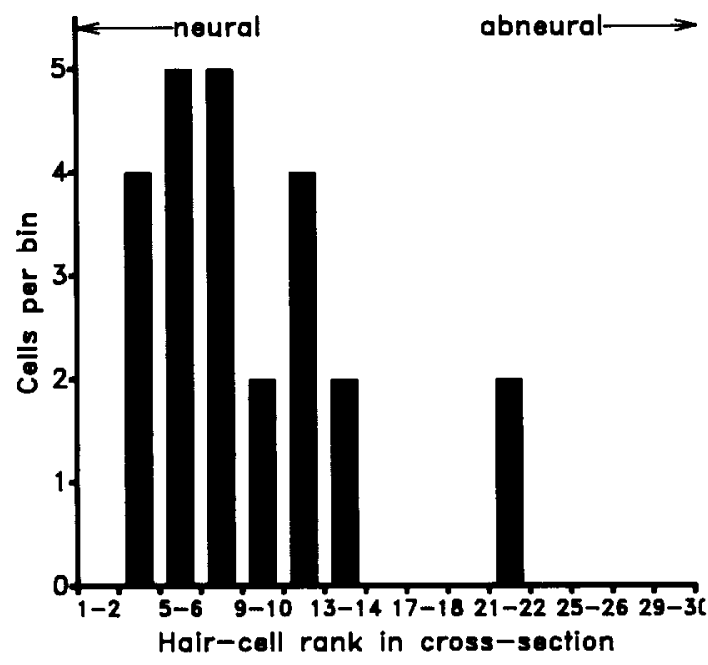

Fig. 5. Distribution of the ranks of hair cells innervated by labelled fibres ( $N=24$ from 21 papillae), determined from cross sections by counting from neural to abneural.

parameters. Fig. 8 shows the discharge-rate threshold at $\mathrm{CF}$ as a function of hair cell rank. The distribution demonstrates a tendency for

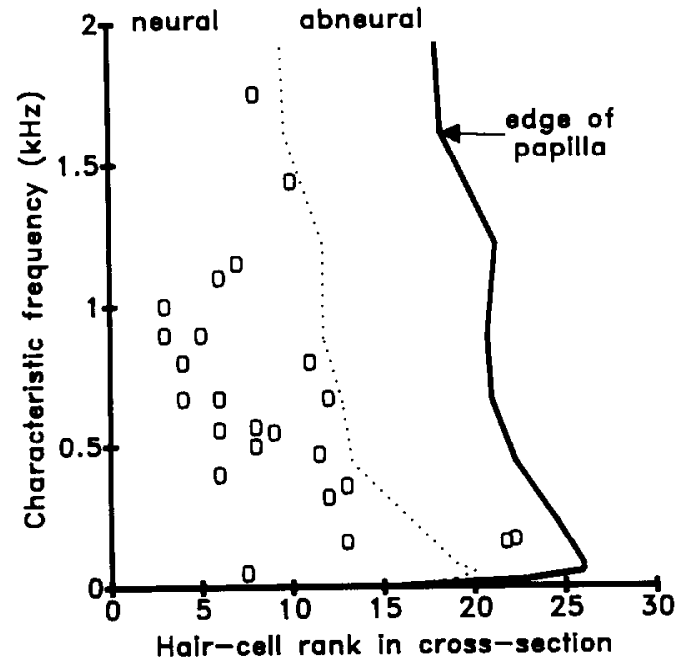

Fig. 6. The CF versus the rank of innervated hair cells. The mean between the extremes is plotted in cases of more than one cell labelled after a single cobalt injection. The heavy line shows the abneural border of the papilla as determined from a serially-sectioned reference specimen. The dotted line shows the position of hair cells with a length-width ratio of $1: 1$, the soma of hair cells on the left of the dotted line is taller than their apical diameter, the soma of hair cells on the right side of the line is shorter than their apical diameter.

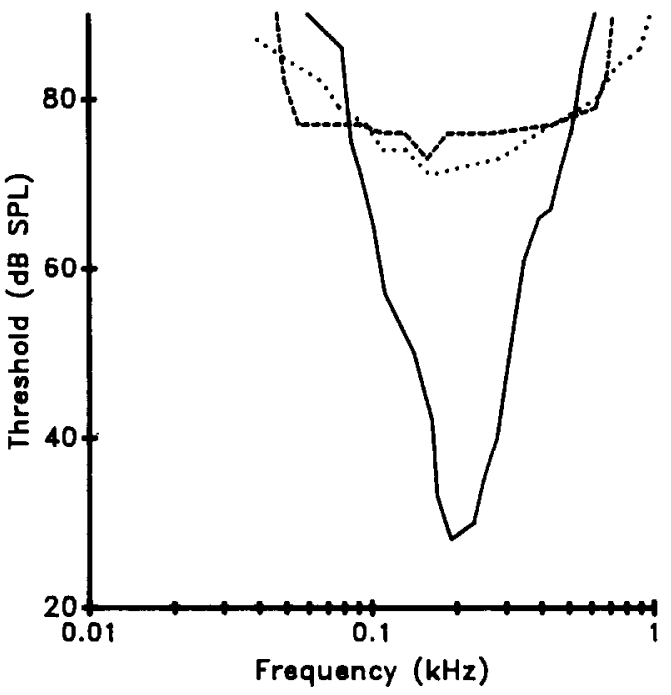

Fig. 7. The tuning curves of the two cells innervating abneurally-lying hair cells near the apical end (dashed and dotted) compared with the tuning curve of a cell responsive in a similar frequency range but innervating a neurally-lying hair cell (heavy line).

threshold to increase with distance from the neural side of the papilla $(N=24, r=0.66, P<$ 0.001 ). The trend is also consistent if the two exceptional cells innervating abneurally-lying hair cells are excluded $(N=22, r=0.55, P<0.01)$. In

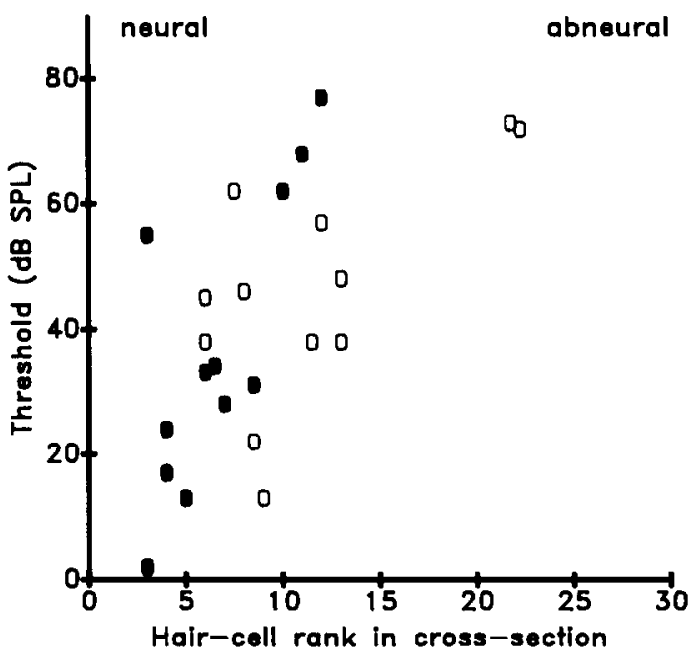

Fig. 8. Thresholds at CF of fibres as a function of the rank of the contacted hair cell. Open symbols represent cells with CFs below $0.6 \mathrm{kHz}$, filled symbols indicate CFs between 0.6 and 1.8 $\mathrm{kHz}$, where the audiogram of the starling is essentially flat. 
order to minimize possible external influences on the distribution (e.g. the effect of the middle-ear transfer function at extreme frequencies) the analysis was restricted to cells with a CF between 0.6 and $1.8 \mathrm{kHz}$, where the audiogram of the starling is rather flat (Kuhn et al., 1982). These are plotted with filled symbols. The correlation of threshold and position within this group is also highly significant $(N=12, r=0.76, P<0.01)$. Here, the linear regression indicates an almost $6 \mathrm{~dB}$ threshold increase for each hair cell proceeding from neural to abneural.

The $Q_{10 \mathrm{~dB}}$-value showed no clear correlation with the rank of the innervated hair cell (Fig. 9). There was no significant correlation within the group of fibres innervating neural hair cells ( $N=$ $21, r=-0.08, P>0.05)$. In addition, the spontaneous discharge rate showed no correlation with the rank of the innervated hair cell (Fig. 10; $N=24, r=-0.1, P>0.05$ ). Although the spontaneous rates were estimated over short time periods during the presentation of ineffective tone stimuli, they were, with an over-all average of 49 spikes/s, similar to more extensive data reported for the starling (Manley et al., 1985).

High-power magnification of the stained terminals of unambiguous cobalt injections in 10 cells revealed that the nerve fibres contact the hair cell at the extreme basal end (e.g. Fig. 4b). In 5 other

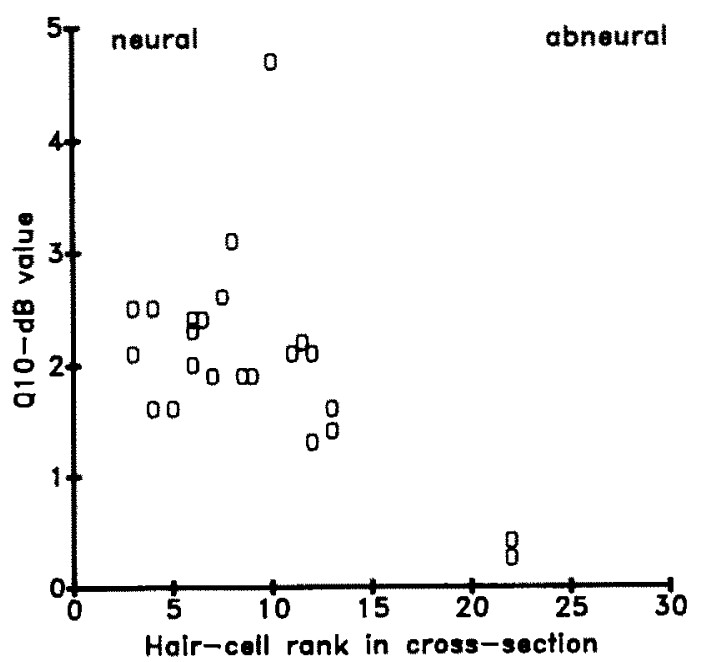

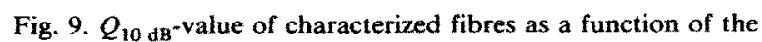
rank of the contacted hair cell.

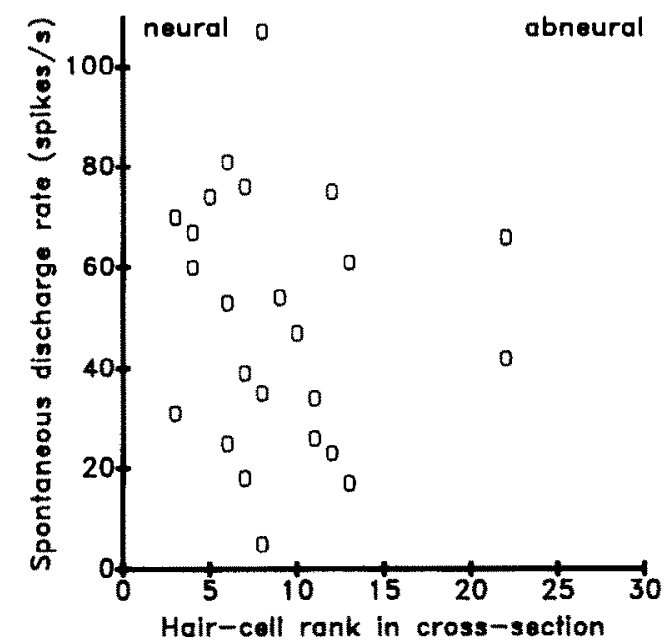

Fig. 10. Spontaneous discharge rate of characterized fibres as a function of the rank of the contacted hair cell.

cases, the stained fibres contacted the hair cell within the baso-lateral half of the cell body. No obvious functional differences were detected between fibres innervating hair cells at the extreme basal end and those terminating on the lateral side of the cell body.

\section{Discussion}

Labelling of auditory afferents has been performed in a variety of mammals (Liberman, 1982b; Robertson, 1984; Kössl and Vater, 1985) and in the chick (Manley et al., 1987a). These studies used the horseradish-peroxidase (HRP) technique to determine the synaptic input of functionallycharacterized neurons. However, initial staining experiments in the starling, using the same techniques and the same set-up as Manley et al. (1987a) were unsuccessful. HRP injections in the starling either caused no stains or staincd diffuscly many fibres which terminated on hair cells covering $30 \%$ or more of the total papillar length (unpublished observations). The difficulty of obtaining dark unambiguous stains in 3-week-old chicks as compared to 2-day-old chicks has already been reported (Manley et al., 1987a). This apparently age-dependent effect on the quality of HRP stains may be even more pronounced in adult starlings, and might be a consequence of progressive myelination during the first 8-12 weeks after 
hatching (Schifferli, 1948; Fermin and Cohen, 1984).

The failure of the HRP-technique was overcome by the successful adaption of the single-cell cobalt technique (Köppl and Gleich, 1988) previously used in invertebrates (Pitman et al., 1972; Bacon and Altman, 1977). This technique gives unambiguous single-cell stains or stains only a few cells innervating hair cells within a very restricted area of the basilar papilla (Fig. 1) without requiring intracellular recording.

The frequency distribution shown in Fig. 2 clearly demonstrates a tonotopic arrangement of the starling's basilar papilla, but also displays a large scatter. The error in measuring the distance of labelled terminals from the apical end of the papilla was determined to be on average $3 \%$, while the CF was determined using frequency steps of 0.2 octaves, resulting in an accuracy of 0.1 octaves. Even considering these errors of measurement, there remains a substantial unexplained scatter. One component introducing scatter may be the fact that data were pooled from 25 individual cochleae. In addition, deterioration of the preparation during recording could also play a role. In mammals, traumata of the inner ear cause a reduction of CF (Liberman, 1984; Robertson et al., 1980). Evidence for similar effects in the starling was found in one cell, where a $30 \mathrm{~dB}$ threshold increase, due to a fall in perilymph level, caused a 0.1-octave reduction of CF (unpublished observation). Another important factor contributing to the scatter might be the temperature of the cochlea. Although the core temperature of the birds was kept close to $40^{\circ}$, it was not possible to determine the actual temperature of the cochlea. Differing room temperatures and evaporation from the incision near the recording site might cause varying degrees of cooling, which in turn would significantly influence the CF of the cells under investigation (Schermuly and Klinke, 1985).

The frequency distribution of the stained terminals within the starling cochlea can be reasonably fit by three different functions (Fig. 2c), with the logarithmic function giving the best correlation. It is not easy to determine the frequency extremes on the papilla. In this study $75 \%$ of the cells had CFs below $1 \mathrm{kHz}$ and only 2 cells with a CF above 1.5 $\mathrm{kHz}$ were encountered, so that most stained fibres innervated hair cells in the apical half of the papilla. The highest frequencies mapped on the starling's papilla can, however, be estimated from other studies. The audiograms measured by Kuhn et al. (1982) and Okanoya and Dooling (1987) both show a dramatic increase of threshold of more than $70 \mathrm{~dB}$ per octave above $6 \mathrm{kHz}$, which is in the range of high-frequency slopes obtained in single-fibre recordings (Manley et al., 1985). Similar audiograms for the starling were obtained by Konishi (1970) by measuring the CF of a great number of cells within the primary auditory nuclei. Here, the highest CFs encountered were around 6 $\mathrm{kHz}$. It seems reasonable to assume that the highest frequency mapped on the starling's basilar papilla is near $6 \mathrm{kHz}$, whereas the lowest frequencies are around $0.05 \mathrm{kHz}$. Thus, none of the functions shown in Fig. $2 c$ gives a comlete correct description of the tonotopic frequency distribution on the starling's basilar papilla. A simple logarithmic function, with equal space devoted to each octave, does fit the data of single-fibre stains obtained in the low-frequency area reasonably, but can not account for the high frequency distribution on the papilla. Thus one has to assume that, as indicated by the smoothed, weighted average (Fig. 2d; Cleveland, 1979), octaves in the high frequency area above $1 \mathrm{kHz}$ occupy more space per octave as compared to lower frequencies. An increased mapping constant for high frequencies as compared to low frequencies has also been described for different mammals (Ehret, 1977; Liberman, 1982a; Wright, 1984), chicken (Manley et al., 1987a) and the bobtail lizard (Manley et al., 1988a). It seems to be a general feature of vertebrate hearing organs which extended their high frequency hearing range above $1-2 \mathrm{kHz}$ by an elongation of the sensory epithelium.

One reason for the different mapping constants of high and low frequency areas might be a difference in the mechanisms responsible for frequency selectivity (Manley, 1986). There is evidence for an electrical tuning mechanism based on the membrane properties of individual hair cells in the low-frequency range (below $1-1.5 \mathrm{kHz}$ ) in the frog (Rana temporaria; Pitchford and Ashmore, 1987), the red-eared turtle (Crawford and Fettiplace, 1981), the tokay gecko (Manley, 1979, Eatock and Manley, 1981) the caiman (Fuchs and Evans, 
1988), the chick (Fuchs, 1988) and the starling (Manley and Gleich, 1984; Gleich, 1987). This allows substantial differences in the CF of neighbouring hair cells, as it is an independent property of the individual hair cell membrane (Manley, 1986). For higher frequencies, where such an electrical mechanism is apparently no longer operative, the frequency selectivity is probably determined by gradual changes in mechanical properties of the hearing organ. The mechanisms of mechanical tuning, however, occupy more space on the epithelia, as, due to lateral mechanical coupling (e.g. via the tectorial membrane), the CFs of neighbouring hair cells cannot in general be independent from each other (Manley et al., 1988b). The finding of a compressed frequency map below $1 \mathrm{kHz}$ in the cat (Liberman, 1982a), where electrical tuning is unlikely, is not easy to explain on this basis (Manley, 1986). However, frequency information is coded in the phase-locked discharges of low-frequency fibres, which has been demonstrated in all vertebrate classes (Fay, 1978; Narins and Hillery, 1983; Smolders and Klinke, 1986; Manley et al., 1988c; Rose and Weiss, 1988; Gleich and Narins, 1988; Anderson et al., 1971). Within the frequency range of good phase locking, place related frequency coding would be less important.

In the starling, two labelled cells innervated abneurally-lying hair cells near the apical end of the papilla (Figs. 5 and 6), and one of these fibres was the only one which branched and innervated a number of hair cells (Fig. 3). These two fibres had rather unusual response patterns when compared to fibres innervating neurally-lying tall hair cells and which responded in similar frequency ranges (Fig. 7). They share a number of features with fibres innervating apical, abneural hair cells described by Schermuly and Klinke (1988) as 'infrasound receptors' in the pigeon. The starling cells did not, however, respond to similar extremely low frequencies (below $0.05 \mathrm{kHz}$ ). This difference is probably the result of the obvious anatomical specializations of the apical end of the pigeon cochlea as compared to the starling (Gleich and Manley, 1988). Abneural hair cells in the apical part of the cochlea of at least some birds species thus apparently form a specialized system responsible for the superior perception of frequen- cies below $0.1 \mathrm{kHz}$ (Kreithen and Quine, 1979; Schermuly and Klinke, 1988).

The criteria for the classification of hair cells as tall or short are somewhat controversial. Takasaka and Smith (1971) included in their definition the ratios of height and width of the cell body and the cuticular plate. The innervation pattern was included by $v$. Düring et al. (1985) to discriminate between the hair cell groups. As all these criteria are arbitrarily selected but not applicable to the present sectioned material, a $1: 1$ ratio of hair cell height and diameter was chosen to delineate hair cell types. However, the extreme forms change gradually over the width of the papilla and no obvious border can be found between the two hair cell types.

The observation of Manley et al. (1987a), that auditory active afferents in the chick exclusively innervate (each fibre contacts only one hair cell) tall hair cells was confirmed and further quantified and confirmed in the starling; only two exceptional cells were found near the apical end (see discussion above; Figs. 5 and 6). This is a strong functional parallel to the mammalian inner ear, where active auditory afferents exclusively contact inner hair cells and are not branched (Liberman 1982b, Robertson, 1984). In mammals, the afferents to the outer hair cells form $5-10 \%$ of the whole complement, and they are unmyelinated and thinner than the afferents to inner hair cells (Spoendlin, 1979; Berglund and Ryugo, 1987). Their lack of myelination, their small size, and small number as well as the absence of spike discharges even to high intensity sound make it difficult to stain these fibres by single-cell labelling techniques (Robertson, 1984).

In mammals two different cell populations (type I and type II) have been defined according to their diameter and myelination (Spoendlin, 1979). Similar cell types, which might innervate tall and short hair cells respectively, have not been described in birds (Boord, 1969; Takasaka and Smith, 1971; Fermin and Cohen, 1984; Whitehead and Morest, 1985). In addition, v. Düring et al. (1985) estimated that the short hair cells receive $16-21 \%$ of all afferents. Thus one might expect that in birds the chance of recording from afferents to short hair cells should be higher than for the outerhair-cell fibres in mammals. At the present time, 
there is no real explanation for the lack of characterized and stained fibres running to short hair cells in the starling and the chick (Manley et al., 1987a). v. Düring et al. (1985) report that up to 6 short hair cells are contacted by a single afferent fibre. Their estimates of the afferent innervation of short hair cells are based on the assumption, made from sectioned material, that on average 3 short hair cells are contacted by an afferent fibre. Determining the morphology and branching pattern of a neuron by studying sections demands a complete reconstruction of the termination area with ultrathin serial sections in order to determine the complete branching pattern, and thus restricts the quantitative study of a great number of cells. In addition, the area occupied by tall hair cells described in the chick by v. Düring et al. (1985; they use the term inner hair cells), is clearly smaller than previously described by Tanaka and Smith (1978). This is due to the different, arbitrarily-chosen criteria for discriminating hair cell populations. Considering that the percentage of short hair cells under the present criteria is smaller than given by v. Düring et al. (1985) and the possibility that the short hair cell afferents contact on average more than 3 hair cells each, then the proportion of afferents innervating short hair cells in the bird could reduce to well below $10 \%$, as in mammals. Thus the lack of labelled afferents could be partly a sampling error, which would be reinforced if these fibres, as in the guinea pig (Robertson, 1984), do not normally show spike discharges in response to physiological stimulus levels.

The larger number of tall hair cells in a cross section as compared to the single row of inner hair cells in mammals makes it possible to investigate the influence of the location of an innervated hair cell across the width of the epithelium. No systematic effects of the hair cell rank (distance from the neural side) on the spontaneous discharge rate (Fig. 10) or on the $Q_{10 \mathrm{~dB}}$-value (Fig. 9) were detected. However, a surprisingly strong effect of hair cell rank on the threshold of the respective cells became obvious (Fig. 8). This effect is not due to a change in overall threshold with $\mathrm{CF}$; for example there are more tall hair cells with higher ranks in a cross-section at the apical (lowfrequency) end where thresholds are higher than in the more basal mid-frequency range (Fig. 6) where thresholds are lower. A threshold increase with hair cell rank is very prominent for cells in the frequency range between 0.6 and $1.8 \mathrm{kHz}$ (filled symbols in Fig. 8), where the audiogram of the starling is reasonably flat (Kuhn et al., 1982). Thus fibres innervating hair cells well onto the neural limbus are more sensitive to sound than those innervating hair cells closer to or upon the free basilar membrane. The threshold increase is almost $6 \mathrm{~dB}$ per cell, as revealed by linear regression through the data of the $0.6-1.8 \mathrm{kHz}$ group.

Although the mechanisms contributing to this phenomenon are not clear at the moment, it indicates that the great spread of thresholds (more than $50 \mathrm{~dB}$ ) found in cochlear ganglion cells of any one starling at a particular frequency is rather normal than the result of a poor physiological condition (Manley et al., 1985). The efficiency of synaptic and neural transmission could contribute to a rise in threshold, but there is no correlation between the hair cell rank and the spontaneous discharge rate (Fig. 10). The gradual change of hair cell orientation from the neural side to the center of the starling papilla (Gleich and Manley, 1988) might contribute to the effect under the assumption that the stimulus acts in a strictly radial direction. The maximal rotation of the hair cell orientation towards the apex is, in the respective frequency range, up to $70^{\circ}$. If only the stimulus component in the direction of the hair cell orientation is effective for the individual hair cell (Hudspeth and Jacobs, 1979), this could cause a threshold increase of 1-2 dB per cell when proceeding from the neural side to the middle of the papilla, but cannot explain the observed increase of $6 \mathrm{~dB}$ per cell. The increase of threshold from neural to abneural is probably due to a complex interaction of different structures within the cochlea, whereby the tectorial membrane probably plays an important role. Otherwise it is hard to understand how the hair cells on the extreme neural side of the papilla, and sitting on the cartilaginous neural limbus, exhibit such a high sensitivity to sound.

Structural parallels between avian tall and mammalian inner hair cells and the short and outer hair cells respectively have been discussed elsewhere (Manley et al., 1988b). The observation that active auditory afferents in the starling and 
the chicken (Manley et al., 1987a) innervate almost exclusively tall hair cells is a functional parallel to the situation in mammals (Liberman 1982b, Robertson, 1984). Avian tall and mammalian inner hair cells both transmit information about sound from the inner ear to the brain. There is some evidence in mammals that the outer hair cells act as electromechanical transducers which influence sensitivity and frequency selectivity of the inner hair-cell responses (Manley, 1986; Mountain, 1986). The present data cannot address the question as to whether avian short hair cells have similar functions to mammalian outer hair cells. However, the observation that otoacoustic emissions are measurable in the starling's ear canal (Manley et al., 1987b) does provide evidence for electromechanical transduction in the starling cochlea.

\section{Acknowledgements}

I thank G.A. Manley for his abundant support and critical discussion which made this study possible. Thanks are also due to B. Böhm and B. Seibel for technical assistance and to G. Klump and $H$. Oeckinghaus for commenting on the manuscript. Supported by the Deutsche Forschungsgemeinschaft, SFB 204 'Gehör'.

\section{References}

Anderson, D.J., Rose, J.E., Hind, J.E. and Brugge, J.F. (1971) Temporal position of discharges in single auditory nerve fibres within the cycle of a sinewave stimulus: frequency and intensity effects. J. Acoust. Soc. Am. 49, 1131-1139.

Bacon, J.P. and Altman, J.S. (1977) A silver intensification method for cobalt-filled neurones in wholemount preparations. Brain Res. 138, 359-363.

Berglund, A.M. and Ryugo, D.K. (1987) Hair cell innervation by spiral ganglion neurons in the mouse. J. Comp. Neurol. $255,560-570$.

Boord, R.L. (1969) The anatomy of the avian auditory system. Ann. New York Acad.Sci. 167, 186-198.

Carrol, R.L. (1988) Vertebrate paleontology and evolution. Freeman, N.Y.

Chen, C.S. and Anderson, L.M. (1985) The inner ear structures of the echidna - an SEM study. Experientia 41, 1324-1325.

Cleveland, W.S. (1979) Robust locally weighted regression and smoothing scatterplots. J. Am. Stat. Ass. 74, 829-836.

Crawford, A.C. and Fettiplace, R. (1981) An electrical tuning mechanism in turtle cochlear hair cells. J. Physiol. 312, $377-412$.
Eatock, R.A. and Manley, G.A. (1981) Auditory nerve fibre activity in the tokay gecko: II. Temperature effect on tuning. J. Comp. Physiol. 142, 219-226.

Ehret, G. (1977) Comparative psychoacoustics: perspectives of peripheral sound analysis in mammals. Naturwissenschaften. $64,461-470$.

Fay, R.R. (1978) Coding of information in single auditory-nerve fibres of the goldfish. J. Acoust. Soc. Am. 63, 1978.

Fermin, C.D. and Cohen, G.M. (1984) Development of the embryonic chick's statoacoustic ganglion. Acta Otolaryngol. 98, 42-52.

Fuchs, P.A. (1988) Electrical tuning in hair cells isolated from the chick cochlea. J. Neurosci. 8, 2460-2467.

Fuchs, P.A. and Evans, M.G. (1988) Evidence for electrical tuning in hair cells isolated from the alligator cochlea. Abstr. Eleventh ARO Res. Meet. 16.

Gleich, O. (1987) Electrical tuning in the avian inner ear. Abstr. Tenth ARO Res. Meet. 22-23.

Gleich, O. and Manley, G.A. (1988) Quantitative morphological analysis of the sensory epithelium of the starling and pigeon basilar papilla. Hear. Res. 34, 69-87.

Gleich, O. and Narins, P.M. (1988) The phase response of primary auditory afferents in a songbird (Sturnus vulgaris L.). Hear. Res. 32, 81-91.

Hudspeth, A.J. and Jacobs, R. (1979) Stereocilia mediate transduction in vertebrate hair cells. Proc. Natl. Acad. Sci. U.S.A. 76, 1506-1509.

Klinke, R. and Pause, M. (1980) Discharge properties of primary auditory fibres in Caiman crocodilus: Comparisons and contrasts to the mammalian auditory nerve. Exp. Brain Res. 38, 137-150.

Köppl, C. and Gleich, O. (1988) Cobalt labelling of single primary auditory neurones: an alternative to HRP. Hear. Res. 32, 111-117.

Kössl, M. and Vater, M. (1985) The cochlear frequency map of the mustache bat, Pteronotus parnellii. J. Comp. Physiol. A 157, 687-697.

Konishi, M. (1970) Comparative neurophysiological studies of hearing and vocalization in songbirds. Z. Vergl. Physiol. 66, 257-272.

Kreithen, M.L. and Quine, D.B. (1979) Infrasound detection by the homing pigeon: a behavioural audiogram. J. Comp. Physiol. 129, 1-4.

Kuhn, A., Müller, C.M., Leppelsack, H.-J. and Schwartzkopff, J. (1982) Heart rate conditioning used for determination of auditory threshold in the starling. Naturwissenschaften 69 , 245-246.

Leake, P.A. (1977) SEM observations of the cochlear duct in Caiman crocodilus. Scanning Electron Microsc. 2, 437-444.

Liberman, M.C. (1982a) The cochlear frequency map for the cat: labeling auditory-nerve fibres of known characteristic frequency. I. Acoust Soc. Am. 72, 1441-1449.

Liberman, M.C. (1982b) Single-neuron labeling in the cat auditory nerve. Science 216, 1239-1241.

Liberman, M.C. (1984) Single-neuron labeling and chronic cochlear pathology. I. Threshold shift and characteristicfrequency shift. Hear. Res. 16, 33-41.

Lim, D.J. (1986) Functional structure of the organ of Corti: a review. Hear. Res. 22, 117-146. 
Manley, G.A. (1979) Preferred intervals in the spontaneous activity of primary auditory neurones. Naturwissenschaften 66,582 .

Manley, G.A. (1986) The evolution of the mechanisms of frequency selectivity in vertebrates. In: B.C.J. Moore and R.D. Patterson (Eds.), Auditory Frequency Selectivity, Plenum, New York and London, pp. 63-72.

Manley, G.A., Brix, J., Gleich, O., Kaiser, A., Köppl, C. and Yates, G. (1988a) New aspects of comparative peripheral auditory physiology. In: J. Syka and R.B. Masterton (Eds.), Auditory Pathway - Structure and Function, Plenum Press, London, New York, pp. 3-12.

Manley, G.A., Gleich, O., Brix, J. and Kaiser, A. (1988b) Functional parallels between hair cell populations of birds and mammals. In: H. Duijhuis, J.W. Horst, H.P. Wit (Eds.), Basic Issues in Hearing, Academic Press, London, pp. 64-71.

Manley, G.A., Yates, G.K., Köppl, C. and Johnstone, B.M. $(1988 \mathrm{c})$ Response delays in auditory-nerve fibres of bobtail lizard in the absence of a travelling wave. Abstr. Eleventh ARO Res. Meet. 241.

Manley, G.A., Brix, J. and Kaiser, A. (1987a) Developmental stability of the tonotopic organization of the chick's basilar papilla. Science 237, 655-656.

Manley, G.A., Schulze, M. and Oeckinghaus, H. (1987b) Otoacoustic emissions in a song bird, 26, 257-266.

Manley, G.A., Gleich, O., Leppelsack, H.-J. and Oeckinghaus, H. (1985) Activity patterns of cochlear ganglion neurones in the starling. J. Comp. Physiol. A 157, 161-181.

Manley, G.A. and Gleich, O. (1984) Avian primary auditory neurones: the relationship between characteristic frequency and preferred intervals. Naturwissenschaften 71, 592-594.

Miller, M.R. (1985) Quantitative studies of auditory hair cells and nerves in lizards. J. Comp. Neurol. 232, 1-24.

Mountain, D.C. (1986) Electromechanical properties of hair cells. In: R.A. Altschuler, R.P. Bobbin and W.H. Douglas (Eds.), Neurobiology of Hearing: the Cochlea, Raven Press, New York.

Narins, P.M. and Hillery, C.M. (1983) Frequency coding in the inner ear of anuran amphibians. In: $R$. Klinke and $R$. Hartmann (Eds.), Hearing - Physiological Bases and Psychophysics, Springer-Verlag, Berlin, pp. 70-76.

Okanoya, K. and Dooling, R.J. (1987) Hearing in passerine and psittacine birds: a comparative study of absolute and masked auditory thresholds. J. Comp. Psychol. 101, 7-15.

Pitchford, S. and Ashmore, J.F. (1987) An electrical resonance in hair cells of the amphibian papilla of the frog Rana temporaria. Hear. Res. 27, 75-85.

Pitman, R.M., Tweedle, C.D. and Cohen, M.I. (1972) Branching of central neurons: intracellular cobalt injection for light and electron microscopy. Science 176, 412-414.
Robertson, D. (1984) Horseradish peroxidase injection of physiologically characterized afferent and efferent neurones in the guinea pig spiral ganglion. Hear. Res. 15, 113-121.

Robertson, D., Cody, A.R., Bredberg, G. and Johnstone, B.M. (1980) Response properties of spiral ganglion neurons in cochleas damaged by direct mechanical trauma. J. Acoust. Soc. Am. 67, 1295-1303.

Rose, C. and Weiss, T.F. (1988) Frequency dependence of synchronization of cochlear nerve fibers in the alligator lizard: Evidence for a cochlear origin of timing and nontiming neural pathways. Hear. Res. 33, 151-167.

Sachs, M.B., Young, E.D. and Lewis, R.H. (1974) Discharge patterns of single fibres in the pigeon auditory nerve. Brain Res. 70, 431-447.

Schermuly, L. and Klinke, R. (1985) Change of characteristic frequency of pigeon primary auditory afferents with temperature. J. Comp. Physiol. 156, 209-211.

Schermuly, L. and Klinke, R. (1988) Single fibre staining of infrasound sensitive neurones in the pigeon inner ear. Pflügers Arch. Suppl. 411, R168.

Schifferli, A. (1948) Ueber Markscheidenbildung im Gehirn von Huhn und Star. Rev. Suisse Zool. 55, 117-212.

Smolders, J.W.T. and Klinke, R. (1986) Synchronized responses of primary auditory fibre-populations in Caiman crocodilus (L.) to single tones and clicks. Hear. Res. 24, 89-103.

Spoendlin, H. (1979) Neural connections of the outer hair cell system. Acta Otolaryngol. 87, 381-387.

Takasaka, T, and Smith, C.A. (1971) The structure and innervation of the pigeon's basilar papilla. J. Ultrastruct. Res. $35,20-65$.

Tanaka, K. and Smith, C.A. (1978) Structure of the chicken's inner ear: SEM and TEM study, Am. J. Anat. 153, 251-272.

v. Düring M., Andres K.H. and Simon K. (1985) The comparative anatomy of the basilar papillae in birds. Fortsch. $d$. Zool. 30, 681-685.

v. Düring M., Karduck, A. and Richter, H.-G. (1974) The fine structure of the inner ear in Caiman crocodilus. Z. Anat. Entw.-Gesch. 145, 41-65.

Whitehead, M.C. and Morest, D.K. (1985) The development of innervation patterns in the avian cochlea. Neuroscience 14, 255-276.

Wright, A. (1984) Dimensions of the cochlear stereocilia in man and guinea pig. Hear. Res. 13, 89-98.

Zar, H.J. (1974) Biostatistical analysis. Prentice-Hall Inc., Englewood Cliffs, N.J. 